\title{
Organising the metals and nonmetals
}

\author{
René E. Vernon ${ }^{1}$ \\ Published online: 5 February 2020 \\ (C) The Author(s) 2020
}

\begin{abstract}
The periodic table can be simply demarcated into four classes of metal and four classes of nonmetal. Such a treatment has been obstructed by the traditional view of metalloids as inbetween elements; understandable but needless boundary squabbles; and a group-by-group view of the reactive nonmetals. Setting aside these limiting notions reveals some interesting patterns and facilitates teaching and learning the periodic table.
\end{abstract}

Keywords Classification of elements · Descriptive chemistry · Diagonal relationship · Inorganic chemistry $\cdot$ Introductory chemistry $\cdot$ Metalloids $\cdot$ Periodic table

In this article I traverse and survey the traditional form of periodic table in order to uncover its internal coherence. Along the way I consider the nature of the boundaries and symmetrical relationships between regions; parallels between individual elements; and the didactic utility of these concepts. A key consideration is a re-evaluation of the wilderness that spans the forgotten post-transition metals; the mysterious metalloids; and the terra incognita of the "other nonmetals".

\section{From left to right across the periodic table}

In general, the elements of the periodic table can be divided into metals and nonmetals. A few borderline elements are sometimes identified as metalloids.

Electronic supplementary material The online version of this article (https://doi.org/10.1007/s 1069 8-020-09356-6) contains supplementary material, which is available to authorized users.

René E. Vernon

rene@webone.com.au

1 Canberra, Australia 


\section{Metals}

The metals can be divided into broad classes, as: active metals; transition metals; and frontier metals (Russell and Lee 2005, p. 419). ${ }^{1}$ A fourth class, the noble metals, is a subset of the transition metals (MacKay et al. 2018; Rayner-Canham 2018).

The active metals are here considered to encompass groups $1-3$, the lanthanoids and actinoids, and aluminium in group 3 . They are mostly strongly electropositive metals, with a few of the light actinoids (uranium to americium) being only moderately electropositive.

The transition metals are, for the most part, moderately to weakly electropositive in nature (Kneen et al. 1972, p. 489). A small number, such as zirconium, are more strongly electropositive; several others are chemically very weak (or noble), like platinum, with these representing the noble metals.

The frontier metals, as a class, are adjacent to the dividing line between metals and nonmetals. Most of them, such as tin and bismuth, are chemically weak. A minority are moderately electropositive (zinc, for example) (Kneen et al. 1972, pp. 264, 525). Being adjacent to the non-metals, their crystalline structures tend to show covalent or directional bonding effects, having generally greater complexity or fewer nearest neighbours than other metallic elements (Russell and Lee 2010, p. 5).

In some respects, the frontier metals can be regarded as the forgotten metals. Wikipedia (2019a) records 15 different category names for these elements located between the transition metals and the metalloids, including 'other metals'. The literature is sparse when it comes to holistic treatments of their chemistry.

\section{Non-metals}

\footnotetext{
"The marvellous variety and infinite subtlety of the non-metallic elements, their compounds, structures and reactions, is not sufficiently acknowledged in the current teaching of chemistry."

JJ Zuckerman and FC Nachod

In Steudel's Chemistry of the nonmetals (1977, preface)
}

After highlighting the halogens and the noble gases, authors have always found it difficult to treat the remaining nonmetals on a holistic rather than group-by-group basis. Thus, in a textbook, there may be separate sections on hydrogen; carbon; nitrogen and phosphorus; and oxygen, sulfur, and selenium. And some or all of the metalloids may or may not be included in the applicable sections.

A richer, complementary taxonomy is introduced in this article. As the metals have been subdivided into four broad classes, so can the nonmetals be subdivided into like classes of noble gases; corrosive nonmetals; intermediate nonmetals; and metalloids. This results in a balanced 6-5-6-6 distribution of the elements concerned. The characteristics of the

\footnotetext{
${ }^{1}$ Rang (1893) may have been the first author to suggest such a tripartite division. He divided the elements into: A. Groups 1-3, which contained the strongest positive elements; B. Groups 4-10 being “...all remarkable for their molecular combinations"; and C. Groups 10-15 including the "heavy metals that have low melting points". He supplemented these with a fourth set: D. Groups 16-17, which contained the strongest negative elements. Helium aside, the noble gases were not known then.
} 
corrosive nonmetals and intermediate nonmetals are subsequently elaborated in this article, the latter at some length.

It has been known for over 120 years that metalloids have a predominately nonmetallic chemistry (Newth 1894; Friend 1914). With the emergence of the semiconductor industry in the 1950s, and the development of solid-state electronics from the early 1960s, metalloids came to be regarded as "in-between elements" (Rochow 1966; Chedd 1969). They are still widely regarded as such (Miller 2019; Wikipedia 2019b). Some chemistry textbooks (Choppin and Johnsen 1972, p. 347; Moeller et al. 1989, p. 742; Young and Sessine 2000 , p. 849) rightly noted the non-metallic chemistry of the metalloids, and a few authors still do so. Setting aside the confusion surrounding the metalloids, they are here treated as chemically weak nonmetals, consistent with Hawley's Condensed Chemical Dictionary (Larrañaga et al. 2016, p. 988); see also Dingle (2017) for a refreshing interpretation of the status of metalloids, as 'poor non-metals'.

Some chemists and instructors may hesitate treating metalloids as nonmetals. Ontologically speaking, anything not a metal is therefore a nonmetal, and this includes metalloids (Oderberg 2007, p. 97). A binary classification can facilitate the establishment of rules for determining bond types between metals and nonmetals (Roher 2001, pp. 4-6). An objection can be raised that the metalloids arsenic and antimony, being semi-metals in the physics-based sense, reduce their electrical conductivity when heated, as do metals generally. Yet plutonium, which is unambiguously a metal, increases its electrical conductivity when heated in the temperature range of around -175 to $+125{ }^{\circ} \mathrm{C}$ (Russell and Lee 2005, p. 466). While metalloids have a metallic appearance and are semiconductors, or are known in such forms, this is also the case for the nonmetals carbon (as graphite); phosphorus (as the black allotrope), selenium, and iodine. It is ironic that the term 'metalloid' was first popularly used to refer to nonmetals, boron and silicon notably so. ${ }^{2}$ There is nothing so special about metalloids that necessarily warrants placing them in a major class of their own.

\section{Noble gases (6)}

The noble gases are volatile, like most of the corrosive nonmetals to their left, but always electropositive in their compounds, as is usually the case with the metals to their right.

\section{Corrosive nonmetals (5)}

\footnotetext{
"In the United States alone, more than $\$ 10$ billion is lost each year to corrosion... Much of this corrosion is the rusting of iron and steel...The oxidizing agent causing all of this corrosion is usually oxygen."

Joesten MD, Hogg L, and ME Castellion In The world of chemistry (2007, p. 217)
}

Admitted into the corrosive nonmetals club are the most reactive and anionic members of the periodic table: oxygen, fluorine, chlorine, bromine, and iodine. As their collective name indicates, they are all corrosive in their elemental forms. Even breathing air has its

\footnotetext{
${ }^{2}$ In 1811 (p. 258), Berzelius referred to nonmetallic elements as metalloids, in reference to their ability to form oxyanions (Bache 1832, p. 250).
} 
drawbacks. Oxygen is a highly reactive molecule, producing molecules of peroxide $\left(\mathrm{O}_{2}{ }^{2-}\right)$ and superoxide $\left(\mathrm{O}_{2}^{-}\right)$after it reacts during respiration to produce water. These highly reactive forms of oxygen would damage the delicate biological structures within a cell. Consequently, most organisms that breathe air have evolved enzymes to deal with these dangers (Arber et al. 1988). Iodine, in crystalline form or in strong solution, is a severe skin irritant; it is not easily removed from the skin, and the lesions resemble thermal burns with brown staining. Cutaneous absorption may be significant and result in systemic symptoms and death (Hathaway 2004). The corrosive nonmetals tend to form ionic compounds with metals (Cotton et al. 1999; Woodward et al. 1999). ${ }^{3}$ Their oxides are acidic. Compounds of the corrosive nonmetals number among the range of chemicals studied in organic chemistry.

In terms of a less well-known diagonal relationship between chlorine and oxygen, chlorination reactions have many similarities to oxidation reactions. Such reactions tend not to be limited to thermodynamic equilibrium and often go to complete chlorination. They are often highly exothermic. Chlorine, like oxygen, forms flammable mixtures with organic compounds (Kent 2010).

\section{Intermediate nonmetals (6)}

\footnotetext{
"For chemists...the most important feature of an element is its pattern of chemical behaviour, in particular, its tendency toward covalent bond formation (or its preference for cation formation)." Rayner-Canham $\mathrm{G}$ and Overton $\mathrm{T}$ In Descriptive Inorganic Chemistry (2010, p. 29)
}

The intermediate nonmetals are hydrogen, carbon, nitrogen, phosphorus, sulfur, and selenium. They are neither as reactive as the corrosive nonmetals nor as chemically restrained as the weakly nonmetallic metalloids. They form salt-like to covalent compounds with metals or, more exotically, interstitial $(\mathrm{H}, \mathrm{C}, \mathrm{N})$ e.g. tungsten carbide, or borderline intermetallic (P, S, Se) alloys e.g. $\mathrm{Fe}_{3} \mathrm{P}, \mathrm{Ni}_{3} \mathrm{~S}_{2}$, and $\mathrm{Bi}_{2} \mathrm{Se}_{3}$ (Wiberg 1995, pp. 256, 517; et al.). Their oxides are acidic, or neutral $\left(\mathrm{H}_{2} \mathrm{O}, \mathrm{CO}, \mathrm{NO}, \mathrm{N}_{2} \mathrm{O}\right)$. The intermediate metals include the most prolific chain- and ring-forming elements in the periodic table. Covalent combinations of the first five of the intermediate nonmetals (along with the corrosive nonmetal oxygen) make up most biological molecules on Earth.

Nitrogen, with its high ionization energy and high electronegativity (3.04, AllredRochow) may look out of sorts compared to the other intermediate nonmetals. On the other hand, its chemistry is largely covalent in nature; and anion formation is energetically unfavourable due to strong inter-electron repulsions arising from having three unpaired electrons in its outer valence shell, hence its negative electron affinity $(-6.75 \mathrm{~kJ} / \mathrm{mol})$. Along these lines, the electronegativity of nitrogen (equivalent to that of chlorine, at 3.16) has been described as "misleading high" (Phillips and Williams 1965a). Many compounds of nitrogen are less stable than diatomic nitrogen, so nitrogen atoms in compounds seek to recombine if possible and release energy and nitrogen gas in the process, which can be leveraged for explosive purposes.

${ }^{3}$ Oxygen is also capable of forming interstitial alloys with metals. 
Table 1 Periodic table extract showing the chain of relationships linking the intermediate nonmetals

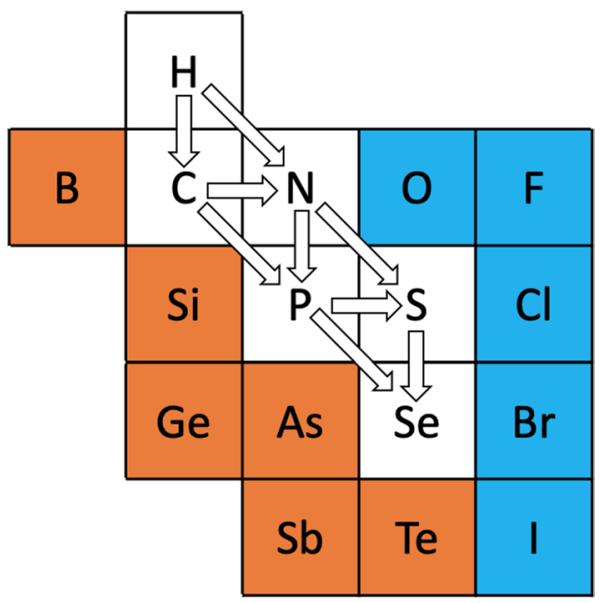

The metalloids, to the left, are shown in red; the corrosive nonmetals are in blue.

Although phosphorus in its most common white form is highly reactive, black phosphorus is the most thermodynamically stable form in ambient conditions and, like nitrogen, is relatively inert. 4

Table 1 shows the vertical, horizontal and diagonal linkages between the intermediate nonmetals.

$\mathbf{H} \rightarrow \mathbf{C}$ Chemical similarities between hydrogen and carbon, including the possible relocation of hydrogen to group 14, have been discussed (Cronyn 2003). They include comparable ionization energies, electron affinities and electronegativity values; half-filled valence shells; and correlations between the chemistry of $\mathrm{H}-\mathrm{H}$ and $\mathrm{C}-\mathrm{H}$ bonds.

$\mathbf{H} \rightarrow \mathbf{N}$ Both are relatively unreactive colourless diatomic gases, with comparably high ionization energies (1312.0 and $1402.3 \mathrm{~kJ} / \mathrm{mol}$ ), each having half-valence subshells, $1 \mathrm{~s}$ and $2 p$ respectively. Like the reactive azide $\mathrm{N}^{3-}$ anion, inter-electron repulsions in the $\mathrm{H}^{-}$ hydride anion (with its single nuclear charge) make ionic hydrides highly reactive. Unusually for nonmetals, the two elements are known in cationic forms. In water the $\mathrm{H}^{+}$"cation" exists as an $\mathrm{H}_{13} \mathrm{O}_{6}{ }^{+}$ion, with a delocalised proton in a central OHO group (Stoyanov et al. 2010). Nitrogen forms an $\mathrm{N}_{5}{ }^{+}$pentazenium cation; bulk quantities of the salt $\mathrm{N}^{+5} \mathrm{SbF}_{6}{ }^{-}$can be prepared. Coincidentally, the $\mathrm{NH}_{4}{ }^{+}$ammonium cation behaves in many respects as an alkali metal anion (Rayner-Canham and Overton 2010 p. 265).

\footnotetext{
${ }^{4}$ When assessing periodicity in the properties of the elements it needs to be borne in mind that the quoted properties of phosphorus tend to be those of its least stable white form rather than, as is the case with all other elements, the most stable form. White phosphorus is the most common, industrially important, and easily reproducible allotrope. For those reasons it is the standard state of the element. Paradoxically, it is also thermodynamically the least stable, as well as the most volatile and reactive form. High quality black phosphorus can be relatively easily prepared from red phosphorus via the addition, with heating, of small quantities of copper, tin, and tin(IV) iodide (Tiouitchi et al. 2019).
} 


\section{The explosive and catenative connections of the intermediate nonmetals}

The fusion of hydrogen provides access to the most explosive form of energy available. Carbon and sulfur are fuel sources in gunpowder. As well as in gunpowder, nitrogen is found in dynamite, nitroglycerine, and TNT. The latter was first used as a yellow dye until its explosive character, which is partly enhanced by the presence of multiple nitrogen units, was discovered. Matches are a form of small-time explosive, in which phosphorus sesquisulfide $\mathrm{P}_{4} \mathrm{~S}_{3}$ can act as a fuel source; old-time strike anywhere matches used white phosphorus, its most thermodynamically unstable form. Selenium has been used in delay fuses for blasting caps and, offhandedly, to fire explosives at a distance via its use in photocells.

The ability to catenate or self-link an element's atoms and form chains and rings is rather marked among the intermediate nonmetals. Carbon is the most prolific catenator among the elements, closely followed by sulfur. Phosphorus readily forms catenae. Selenium does so less readily. Hydrogen and nitrogen may be regarded as poor cousins. That said, the trihydrogen cation $\mathrm{H}_{3}{ }^{+}$is thought to be one of the most abundant ions in the universe. While nitrogen is a reluctant player, long chains have attracted considerable attention in the research field of propellants, explosives, and gas generants. The longest known chain stops at eleven; compounds having five-membered nitrogen rings have been known since $1956 . \mathrm{LiN}_{5}$ is a five-ring nitrogen compound, only recently synthesized.

$\mathbf{C} \rightarrow \mathbf{N}$ With nitrogen, carbon forms an extensive series of nitride compounds including those with high $\mathrm{N}: \mathrm{C}$ ratios, and with structures that are simple $\left(\mathrm{CN}_{12}\right)$; chain-like $\left(\mathrm{C}_{6} \mathrm{~N}_{2}\right.$ for example); graphitic (linked $\mathrm{C}_{6} \mathrm{~N}_{7}$ units); fullerenic $\left(\mathrm{C}_{48} \mathrm{~N}_{12}\right)$ or polymeric $\left(\mathrm{C}_{3} \mathrm{~N}_{3}\right.$ units). Most of the compounds prepared to date also contain quantities of hydrogen (Miller et al. 2017).

$\mathbf{C} \rightarrow \mathbf{P}$ Carbon and phosphorus represent another example of a less-well known diagonal relationship, especially in organic chemistry. Spectacular evidence of this relationship was provided in 1987 with the synthesis of a ferrocene-like molecule in which six of the carbon atoms were replaced by phosphorus atoms (Bartsch et al. 1987). Further illustrating the theme is the extraordinary similarity between low-coordinate trivalent phosphorus compounds (in which phosphorous has less than three nearest neighbours) and unsaturated carbon compounds (in which carbon has at least one double bond, or a triple bond), and related research into organophosphorus chemistry (Rayner-Canham 2011; Dillon et al. 1998).

$\mathbf{N} \rightarrow \mathbf{P}$ Like nitrogen, the chemistry of phosphorus is that of the covalent bond; the two nonmetals rarely form anions. Despite them being in the same group, and the composition of some of their compounds resembling one another, the individual chemistries of nitrogen and phosphorus are very different (Wiberg et al. 2001, p. 686). That said, the two elements form an extensive series of phosphorus-nitrogen compounds having chain, ring and cage structures; the $\mathrm{P}-\mathrm{N}$ repeat unit in these structures bears a strong resemblance to the $\mathrm{S}-\mathrm{N}$ repeat unit found in the wide range of sulfur-nitrogen compounds, discussed next (Roy et al. 1994).

$\mathbf{N} \rightarrow \mathbf{S}$ Nitrogen and sulfur have a diagonal relationship, manifested in like charge densities and electronegativities especially when sulfur is bonded to an electron-withdrawing group. The two elements are able to form an extensive series of seemingly interchangeable sulfur nitrides, the most famous of which, polymeric sulfur nitride, is metallic, and a superconductor below $0.26 \mathrm{~K}$. The cyclic $\mathrm{S}_{3} \mathrm{~N}_{2}{ }^{2+}$ cation, in particular, serves as an exemplar of the similarity of electronic energies between the two nonmetals (Rayner-Canham 2011, p. 126).

$\mathbf{P} \rightarrow \mathbf{S}$ (Se) Phosphorus reacts with sulfur and selenium (and oxygen) to form a large number of compounds. These compounds are characterized by structural analogies derived from the white phosphorus $\mathrm{P}_{4}$ tetrahedron (Monteil and Vincent 1976). 
$\mathbf{S} \rightarrow$ Se Commonalties between sulfur and selenium are abundantly obvious. For example, selenium is found in metal sulfide ores, where it partially replaces sulfur; both elements are photoconductors-their electrical conductivities increase by up to six orders of magnitude when exposed to light (Moss 1952).

Somewhat like the frontier metals, the intermediate nonmetals have represented terra incognita in terms of a holistic treatment. Wikipedia (2019c) records a dozen different organisational arrangements and class names for them, including other nonmetals. To my knowledge this is the first time the relationships among the nonmetals in this part of the periodic table have been delineated in other than a group-by-group or perfunctory manner.

\footnotetext{
The importance of classification ${ }^{5}$

"At any given time, during the historical development of a scientific discipline, classification of available evidence offers itself as the explanandum that asks for a theory (or alternative theories) able to explain it. But this is just one segment in a potentially unending chain of recursive relationships between classification and theory. Theory and classification indeed change over time. As a consequence, the theory that provides explanation for the data organized in a classification at a given time can influence subsequent classificatory effort, and so on. "By means of this a discipline advances: each new pattern raises questions that call for explanations, and each verified phenomenon or fact gives a new pattern" (p. 163). What counts as a fact or a theory is a matter of temporal relativity. The authors' "concern is that we do not replace observation with theory and think that we have made some progress. Science is founded upon empirical observations, no matter how these are tied up with local and cross-disciplinary theoretical commitments or stances. Once we abandon this aspect of science...science becomes little more than a matter of worldviews and epistemic statements of faith" (p. 163)."
}

\section{Metalloids (6)}

The elements commonly recognised as metalloids are boron, silicon, germanium, arsenic, antimony and tellurium (Vernon 2013). As the weakest of the nonmetals they are assigned positive oxidation states in their compounds with nonmetals, and negative oxidation states in their compounds with most metals.

Writing early in the history of intermetallic compounds, the British metallurgist Cecil Desch et al. (1914) observed that "certain non-metallic elements are capable of forming compounds of distinctly metallic character with metals, and these elements may therefore enter into the composition of alloys". He associated silicon, arsenic, and tellurium, in particular, with the alloy-forming elements. Phillips and Williams (1965b) suggested that compounds of silicon, germanium, arsenic, and antimony with B metals, i.e. those in groups 11 onwards, "are probably best classed as alloys". On boron, transition metal borides are often more conductive than the parent metal (Carenco et al. 2013). $\mathrm{TiB}_{2}$, for example, has five times the electrical conductivity of cold-pressed titanium (Grimvall 2005). With lithium, boron is known to form a metallic, malleable, extrudable, and machinable alloy having the composition $\mathrm{Li}_{5} \mathrm{~B}_{4}$, and a silvery metallic lustre (Wang 2005).

Metalloids otherwise form salt-like to more covalent compounds with metals. Their oxides are weakly acidic or amphoteric. Organic compounds of the metalloids fall within scope of the definition of organometallic compounds, as a long standing tradition.

\footnotetext{
5 Minelli, A.: The nature of classification: Relationships and kinds in the natural sciences-By John S. Wilkins and Malte C. Ebach. Systematic Biology. 63 (5), pp. 844-846.
} 
Fig. 1 Periodic table classes of elements
Noble gases

$\mathrm{He}, \mathrm{Ne}, \mathrm{Ar}, \mathrm{Kr}, \mathrm{Xe}, \mathrm{Rn}$

Active metals

Corrosive nonmetals

Groups 1-3, Ln, An, (Al)

$\mathrm{O}, \mathrm{F}, \mathrm{Cl}, \mathrm{Br}, \mathrm{I}$

Transition metals

Most of them

Frontier metals

(Al) Ag, Sn, Bi etc.

\section{$\underline{\text { Intermediate nonmetals }}$}

$\mathrm{H}, \mathrm{C}, \mathrm{N}, \mathrm{P}, \mathrm{S}, \mathrm{Se}$

Metalloids

B, Si, Ge, As, Sb, Te

Noble metals

$\mathrm{Ru}, \mathrm{Rh}, \mathrm{Pd}, \mathrm{Os}, \mathrm{Ir}, \mathrm{Pt}, \mathrm{Au}$

The metalloids represent a further wilderness in the literature, with the last dedicated reference work appearing over 50 years ago (Rochow 1966). Masterton and Slowinski (1977) used three criteria to describe the six elements commonly recognised as metalloids: metalloids have ionization energies of around $200 \mathrm{kcal} / \mathrm{mol}(837 \mathrm{~kJ} / \mathrm{mol})$ and electronegativity values close to 2.0. They also said that metalloids are typically semiconductors, though antimony and arsenic [semimetals from a physics perspective] have electrical conductivities approaching those of metals. Selenium and polonium were suspected as not in this scheme, while astatine's status was uncertain. Astatine has since been predicted to be a full-fledged metal (Hermann et al. 2013).

\section{Boundaries}

As with classification schemes generally, there is some variation and overlapping of properties within and across each class (Jones 2010) shown in Fig. 1. Beryllium, for example, has a crystalline structure showing a mixture of metallic and covalent bonding, and an amphoteric oxide, thereby having some characteristics of a frontier metal (Russell and Lee 2005, p. 171). Sulfur, along with nitrogen, is present in (corrosive) acid rain. Among the noble gases, radon is the most metallic and begins to show some cationic behaviour, which is unusual for a non-metal (Stein 1983).

This point is worth reiterating: there is a spectrum of properties within each class. The distinction between classes is not absolute. Boundary overlaps occur as outlying elements in each class show or begin to show less-distinct, hybrid-like, or atypical properties. As expressed by Nelson (2011):

...care needs to be taken to remember that...[this classification scheme] is only an approximation, and can only be used as a rough guide to the properties of the elements. Provided that this is done, however, it constitutes a very useful classification, and although purists often despise it because of its approximate nature, the fact is that practising chemists make a great deal of use of it, if only subconsciously, in thinking of the chemistry of different elements.

While Nelson was referring to a scheme for classifying the nonmetals according to their electronegativity, the principle is the same. The electronegativity ranges of the eight classes of elements are considered later. 
Table 2 Alt-class names

\begin{tabular}{ll}
\hline Active metals & Hyper metals \\
Transition metals & Working metals \\
Frontier metals & Poor metals \\
Noble metals & High society metals \\
Metalloids & Junior nonmetals \\
Intermediate nonmetals & Respectable nonmetals \\
Corrosive nonmetals & Psycho nonmetals \\
Noble gases & Cup of tea nonmetals \\
\hline
\end{tabular}

With this caveat in mind, the eight classes or their constituents are well enough recognized in the literature or, in the case of the intermediate nonmetals, coalesce after separating out the metalloids and the corrosive nonmetals. The resulting taxonomy represents a more informative way of organizing the nonmetals.

The power of boundary overlaps comes from recognizing the interesting chemistry that they flag rather than squabbling about where one class starts and another ends (Schultz 2010). They can be regarded as linch-pins, in addition to horizontal, diagonal, and vertical relationships, that hold together and affirm the facts and parts of the periodic table as a complex structure (Scerri 2012).

\section{Class names with attitude}

For students or instructors who enjoy more visceral distinctions, Table 2 may be used to convey a stronger impression of the nature of the elements in each class. For group 18 nonmetals as "cup of tea nonmetals", C. S. Lewis said that "Tea should be taken in solitude". This brings to mind an image of the noble gases, quietly sipping tea by themselves.

\section{Periodic table}

The eight classes are depicted in the accompanying periodic table (see the Electronic supplementary material) along with mini-biographies.

The active metals (the s- and f-block metals, group 3, and $\mathrm{Al}$ in group 13) have been further sub-classified as pre-transition metals; rare earths; and actinoids.

Group 3 is shown as bifurcating after yttrium, into a La-Ac branch, and a Lu-Lr branch. This is consistent with the inconclusive distinction between lanthanum and lutetium based on physical, chemical, and electronic properties (Scerri and Parsons 2018).

The classifications of aluminium, silver, and the group 12 metals have been carefully considered. Aluminium, as an active metal, is somewhat of a paradox: "It is a highly electropositive metal... [with a high negative electrode potential" yet "resembles a weak metal in its amphoteric oxide and in the covalent character of many of its compounds." (Steele 1966, p. 60). It could be classed as active metal or a frontier metal. I have chosen to treat it as an active metal in light of its physical similarities (as a light structural metal) to the active metals $\mathrm{Be}$ and $\mathrm{Mg}$; its chemical similarities to the former; and the noble gas core it has in common with the latter, unlike the $\mathrm{d}^{10}$ and $\mathrm{f}^{14} \mathrm{~d}^{10}$ cores of the frontier metals. Silver is shown as a frontier metal. Its chemistry is dominated by its +1 valence state in which it shows generally similar physical and chemical properties to compounds of thallium, a 
main group metal, in the same oxidation state (Rayner-Canham 2018). Zinc, cadmium, and mercury have been included with the frontier metals in light of an abrupt and significant reduction in physical metallic character from group 11 to group 12, and their main group chemistry (Sorensen 1991).

\begin{tabular}{|c|c|c|c|c|c|}
\hline 11 & 12 & 13 & \multirow[t]{2}{*}{14} & \multirow[t]{2}{*}{15} & \multirow[t]{3}{*}{16} \\
\hline $\begin{array}{c}\mathrm{Cu} \\
+1,+2\end{array}$ & $\begin{array}{l}\mathrm{Zn} \\
+2 \\
\end{array}$ & $\begin{array}{l}\mathrm{Ga} \\
+3 \\
\end{array}$ & & & \\
\hline \multirow[t]{2}{*}{$\begin{array}{c}\mathrm{Ag} \\
+1,+3\end{array}$} & $\begin{array}{l}\mathrm{Cd} \\
+2 \\
\end{array}$ & $\begin{array}{c}\text { In } \\
+1, \underline{+3}\end{array}$ & $\begin{array}{c}\mathrm{Sn} \\
+2,+4\end{array}$ & $\begin{array}{c}\mathrm{Sb} \\
+3,+5\end{array}$ & \\
\hline & $\begin{array}{c}\mathrm{Hg} \\
+1, \underline{+2}\end{array}$ & $\begin{array}{c}\mathrm{Tl} \\
+1, \underline{+3}\end{array}$ & $\begin{array}{c}\mathrm{Pb} \\
+2,+4\end{array}$ & $\begin{array}{c}\mathrm{Bi} \\
+\underline{3},+5\end{array}$ & $\begin{array}{c}\mathrm{Po} \\
+2, \underline{+4}\end{array}$ \\
\hline
\end{tabular}

\section{Knight's move relationships ${ }^{6}$}

Several of the frontier metals are further distinguished by a series of such relationships, formed between one element and the element one period down and two groups to its right. Examples:

1. Copper(I) chemistry resembles indium(I) chemistry: "both ions are found mostly in solid-state compounds such as $\mathrm{CuCl}$ and $\mathrm{InCl}$; the fluorides are unknown for both ions while the iodides are the most stable."

2. Aqueous solutions of zinc and tin dichlorides hydrolyze to give insoluble hydroxochlorides $\mathrm{Zn}(\mathrm{OH})$ $\mathrm{Cl}$ and $\mathrm{Sn}(\mathrm{OH}) \mathrm{Cl}$.

3. Indium(III) and bismuth(III) form "parallel complex ions with halide ions (X), of the forms $\mathrm{MX}_{4}{ }^{-}$ and $\mathrm{MX}_{6}{ }^{3-}$;" the two ions "form parallel oxohalides, such as $\mathrm{InOCl}$ and $\mathrm{BiOCl}$, and they both form alums: $\mathrm{M}^{+} \mathrm{M}^{3+}\left(\mathrm{SO}_{4}{ }^{2-}\right)_{2} \cdot 12 \mathrm{H}_{2} \mathrm{O}$, where $\mathrm{M}^{+}$is a large monopositive ion and $\mathrm{M}^{+}$is indium(III) or bismuth(III)."

4. Silver(I) and thallium(I), each being "very low charge ions...have insoluble halides except for the fluorides; both form brick-red insoluble chromates."

5. Copper (a near frontier metal) and mercury share another kind of knight's move relationship (two periods down and one group to the right). Copper $(0)$ and mercury $(0)$ each react with concentrated nitric acid and hot concentrated sulphuric acid to yield copper(II) and mercury(II) ions, and nitrogen dioxide and sulfur dioxide, respectively (Steele 1966, p. 71). Copper(I) and mercury(I), in aqueous solution, are susceptible to disproportionation into copper(II) and mercury(II) (Kneen et al. 1972, pp. 521, 529). In analytical chemistry, copper(II) and mercury(II) appear in the same detection and separation group (Whitten et al. 1988, p. 905). The isoelectronic $\left(\mathrm{d}^{10} \mathrm{~s}^{0}\right)$ oxides of copper $\mathrm{Cu}_{2} \mathrm{O}$ and mercury $\mathrm{HgO}$ each appear yellow or red, depending on the method of preparation (Wiberg et al. 2001, pp. 1257, 1313).

The knight's move relationships arise from similarities in the sizes of ions of different periods due to poor shielding by transition metal $d$ and lanthanoid $f$ electrons, and relativistic effects increasing the stability of lower oxidation states.

In the above periodic table extract the most stable oxidation states are underlined.

The key consideration is that the eight classes provide an economy of description and are beneficial to structuring knowledge and to our understanding of the periodic table landscape (Jones 2010. p. 169).

${ }^{6}$ Rayner-Canham and Overton 2010, pp. 212-215 


\section{4}

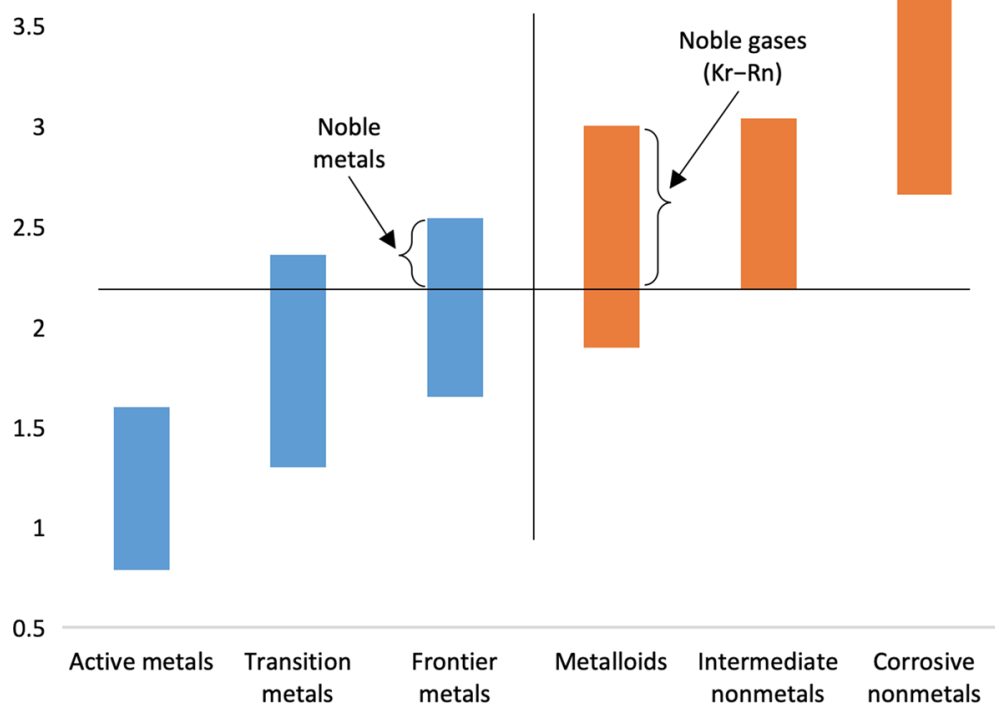

Fig. 2 Electronegativity bars for periodic table element classes

\section{Symmetrical relationships}

Figure 2 depicts the eight classes of elements in the form of bars spanning their lowest and highest Allred-Rochow electronegativity values. The aforementioned boundary overlaps are evident. The noble gas bar spans only radon to krypton since compounds of the lighter noble gases are unknown in ambient or near ambient conditions; even those of krypton are unstable.

Two kinds of approximate symmetry can be discerned, lateral and inverse.

\section{Lateral}

The noble metals and the noble gases are largely reluctant players.

The chemically weak frontier metals and their counterparts, the weakly nonmetallic metalloids, share a proclivity for amphoteric behaviour (as do beryllium and aluminium, being adjacent to the frontier metals). The line between the frontier metals and the metalloids can meander, with polonium and astatine sometimes counted as metalloids, and germanium, and antimony sometimes regarded as (frontier) metals.

\section{Inverse}

The active metals and corrosive nonmetals are reactive exemplars, albeit diametrically opposed in their mechanism of action. That said, the active metals sodium, potassium, rubidium, caesium, and barium can form anions of the form $X_{n}^{-}(n=1$, except $B a=2)$ (Wiberg et al. 2001, pp. 419-421; Dye 1979; Redko et al. 2003), as can the corrosive 
nonmetals chlorine, bromine and iodine form isolable cations: $\mathrm{Cl}_{3}{ }^{+}, \mathrm{Br}_{2}^{+}, \mathrm{Br}_{3}^{+}, \mathrm{BrI}_{5}{ }^{+}$, and $\mathrm{I}_{2}{ }^{+}, \mathrm{I}_{3}{ }^{+}, \mathrm{I}_{4}^{+2}, \mathrm{I}_{5}{ }^{+}, \mathrm{I}_{7}{ }^{+}$and $\mathrm{I}_{15}^{+3}$.

The transition metals represent a "transition" from the active metals to their right and the frontier metals to the left, just as the intermediate nonmetals occupy a changeover zone between the weakly nonmetallic metalloids to their left and the corrosive nonmetals to the right. The transition metals are known for their catalytic properties; the intermediate nonmetals are known for their uses in explosives.

The noble metals show some surprising nonmetallic behaviour; gold sometimes behaves as if it were a halogen, and both gold and platinum are known to form anions in caesium auride $(\mathrm{CsAu})$, and the barium platinides $\left(\mathrm{Ba}_{2} \mathrm{Pt}\right.$ and $\left.\mathrm{BaPt}\right)$. Likewise, the metalloids, as chemically weak nonmetals, show the most metallic character among the nonmetals. For example, on the analogy between boron and metals, Greenwood (2001) commented that:

The extent to which metallic elements mimic boron (in having fewer electrons than orbitals available for bonding) has been a fruitful cohering concept in the development of metalloborane chemistry...Indeed, metals have been referred to as "honorary boron atoms" or even as "flexiboron atoms". The converse of this relationship is clearly also valid...

The same pattern is seen in the set of frontier metals and noble gases. Thus, the heavier (period 6) frontier metals border on nobility:

Because of the increase of nuclear charge across each of the transition series, the $\mathrm{B}$ metals are distinguished from the early A metals by their much weaker tendency to form ions or to form compounds with the non-metals... This feature is particularly marked in the final row of $\mathrm{B}$ metals, $\mathrm{Au}, \mathrm{Hg}, \mathrm{Tl}, \mathrm{Pb}, \mathrm{Bi}$, and Po... where the nuclear charge has been built up across the lanthanoid as well as the third transition series. In some respects, these elements might almost be classed as super-B or C metals (Phillips 1966).

And the noble gases become more metallic going down the group, so much so that radon begins to exhibit some cationic behaviour (cf. astatine, here classed as frontier metal) (Stein 1985; Hermann et al. 2013).

\section{Implications}

The symmetry shown among the electronegativity range bands suggests that the sorting of the metals and nonmetals into the eight classes provides a sound taxonomy, and a basis for further research on analogous relationships between the classes of elements.

The basis of my claim rests on assertions by Jensen (1986, p. 496) and Leach (2013) concerning the classification of the elements and the explanatory power of electronegativity.

On electronegativity, Leach observed that:

"There are such strong correlations between numerous atomic parameters, physical and chemical, that the term "electronegativity" has the effect of integrating them into a single dimensionless number between 0.78 and 4.00. Consequently, the electronegativity of an element can be used to predict/describe/model much of its empirical physical character and chemical behaviour." 
Earlier, Jensen had suggested, with some caution, that any significant classification of the elements had to be based on a "natural system" of some sort, that is, it should arise naturally or spontaneously from a study of the elements' properties rather than being based on some artificial or arbitrarily selected criterion or theoretical preconception.

That electronegativity values correlate well with multiple properties, and that the range bands appear spontaneously, "in symmetry related positions, rather than being imposed beforehand, both suggest that the resulting classification is really a natural one." (Jensen 1986, p. 496).

\section{Parallels}

Some incidental and intriguing parallels can be further seen at the individual element level. Carbon, an intermediate nonmetal, is the most electrically and thermally conducting of the nonmetals (as graphite and diamond respectively) while the frontier metal silver-which exhibits transition metal chemistry in its higher, less stable, oxidation states-is the two-inone counterpart among the metals. (White) phosphorus, an intermediate nonmetal, has the same crystalline structure as the transition metal manganese (Clark and Zaug 2010). Iodine, as a near-metalloid, has a crystalline structure analogous to that of gallium, another nearmetalloid (Greenwood and Earnshaw 1998). Xenon, in the +8 oxidation state, forms a pale yellow explosive oxide, $\mathrm{XeO}_{4}$, while osmium forms a yellow strong oxidizing oxide $\mathrm{OsO}_{4}$. There are parallels in the formulas of the oxyfluorides: $\mathrm{XeO}_{2} \mathrm{~F}_{4}$ and $\mathrm{OsO}_{2} \mathrm{~F}_{4}$, and $\mathrm{XeO}_{3} \mathrm{~F}_{2}$ and $\mathrm{OsO}_{3} \mathrm{~F}_{2}$ (Rayner-Canham and Overton 2010, p. 205). The first compound between a noble metal (gold in this case) and a noble gas (xenon), in the form of tetraxenonogold(II) undecafluoro-diantimonate( $\mathrm{V}) \mathrm{AuXe}_{4}{ }^{2+}\left(\mathrm{Sb}_{2} \mathrm{~F}_{11}{ }^{-}\right)$, was synthesized in 2000. Ironically, the synthesis in 1962 of the first noble gas compound, of approximate composition $\mathrm{XePtF}_{6}$, involved another noble metal (platinum) (Pan et al. 2019).

\section{Didactic utility}

Several features of this article will facilitate its didactic utility namely the use of tradition; analogy; descriptive chemistry; systematics; symmetry; contrast; and aspects of learning theory.

A traditional aspect of teaching the periodic table is to contrast the alkali metals with the halogens. This approach is extended.

Analogies, metaphors, and other types of comparisons used here are common instructional techniques used to help students understand new concepts by linking them to familiar ideas.

In a teaching and learning context, descriptive chemistry (as used here) can enhance theoretical chemistry (Beach 1984). Descriptive inorganic chemistry has been criticized for its potentially monotonous focus on horizontal and vertical trends; the patterns and relationships set out in this article show that the periodic table is much more than the sum of its periods and groups (Rayner-Canham 2000).

A fair amount of coverage of the chemistry of the nonmetals is provided; as noted in the first call out, "The marvellous variety and infinite subtlety of the non-metallic elements, their compounds, structures and reactions, is not sufficiently acknowledged in the current teaching of chemistry". Lacking a systemic approach for organising the nonmetals, 


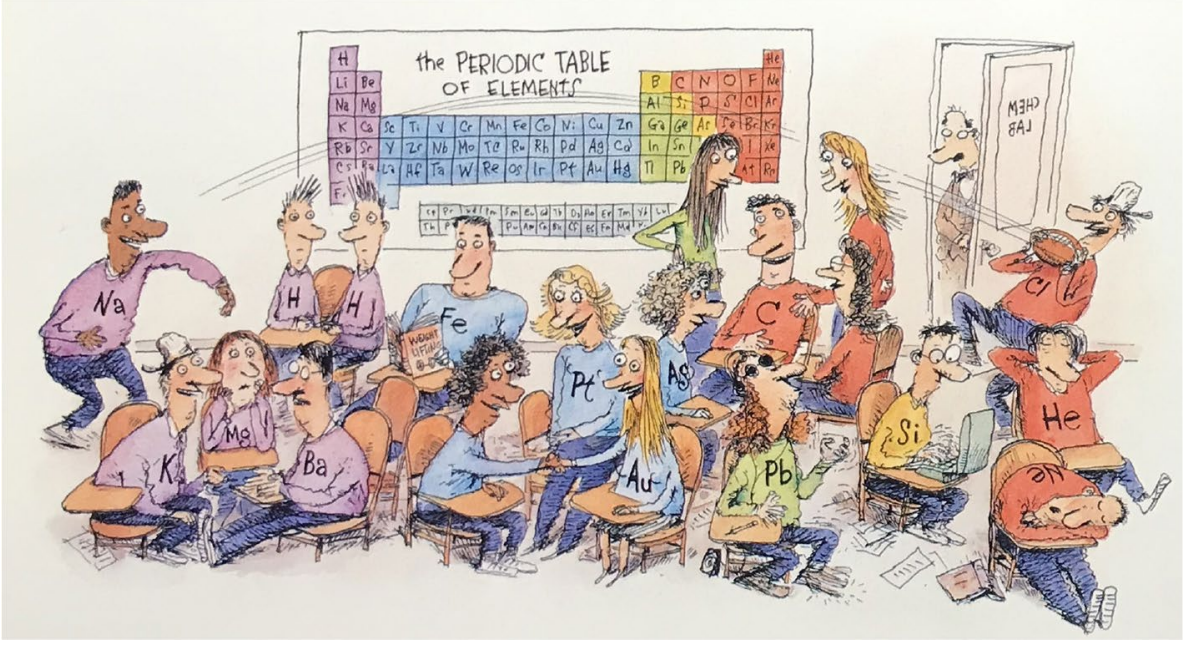

The elements as classroom personality kids (Richard Thompson 1957-2016). Sodium is actively practicing a "salt-formation" passing play with corrosive chlorine, who devours the delivery. Potassium, magnesium and barium are having an active metal huddle. The two hydrogens are hot desking. Iron is reading a weightlifting workout book. Platinum introduces gold to iridium, all three being noble metals. Lead, as a heavy frontier metal, is playing air guitar. Carbon is having a link up with frontier metal silver (masquerading as a transition metal); an unidentified frontier metal; and two "other" nonmetals. Silicon, as a metalloid and a semiconductor, is catching up on an assignment. Helium and neon, having each had a cup of chamomile tea during the break, are sleeping

this is still the case. In a teaching context, and as noted, as well as providing an economy of description the resulting classes are beneficial to the structuring and understanding of knowledge.

The symmetrical relationships seen in the periodic table can facilitate learning since fewer observations are required to describe the applicable system. Further, concepts that possess symmetry can be more easily grasped than those that do not (Randall 2006).

The contrast between the two sets of class names set out in Table 2 helps students to reinforce their learnings (Entwistle 2018).

The accompanying periodic table (see the Electronic supplementary material) incorporates elements of learning theory with its use of annotations to facilitate perceptual grouping; colour to differentiate ideas and direct attention to key topics; and "natural" classes or clusters to organise information and help with content processing (Richey et al. 2010).

\section{Summary}

The metallic and nonmetallic elements of the periodic table can be organised into four paired classes of metals and nonmetals. Consideration of the elements in this manner is enabled by separating out the noble metals from the transition metals, and parsing the reactive nonmetals into corrosive nonmetals, intermediate nonmetals, and metalloids. Proceeding around the resulting taxonomy brings out some pleasing patterns, and facilitates teaching and learning the periodic table. 
Acknowledgements I thank members of Wikipedia: Wikiproject Elements for years of discussion on how to parse the elements, particularly the (exasperating) nonmetals, and Gavin Jared Bala for the eponym of the noble gases as "cup of tea nonmetals". I thank Jess Tauber for pointing out the inverse relationships among the four inside sets of electronegativity range bars; Amy Thompson for permission to use the cartoon by Richard Thompson (1957-2016) of the elements as personality kids; Norbert Pienta for feedback on an early version of this article; and anonymous referees for their helpful comments, suggestions, and support.

Open Access This article is licensed under a Creative Commons Attribution 4.0 International License, which permits use, sharing, adaptation, distribution and reproduction in any medium or format, as long as you give appropriate credit to the original author(s) and the source, provide a link to the Creative Commons licence, and indicate if changes were made. The images or other third party material in this article are included in the article's Creative Commons licence, unless indicated otherwise in a credit line to the material. If material is not included in the article's Creative Commons licence and your intended use is not permitted by statutory regulation or exceeds the permitted use, you will need to obtain permission directly from the copyright holder. To view a copy of this licence, visit http://creativecommons.org/licenses/by/4.0/.

\section{References}

Arber, J., Garner, D., Hasnain, S.: X-rays highlight metals in biology. New Scientist. 21 January, 48-51 (1988) Bache, A.D.: An essay on chemical nomenclature, prefixed to the treatise on chemistry; by. J. J. Berzelius. Am. J. Sci. 22, 248-277 (1832)

Bartsch, R., Hitchcock, P.B., Nixon, J.F.: First structural characterisation of penta- and hexa-phosphorus analogues of ferrocene Synthesis, crystal and molecular structure of the air-stable, sublimable iron sandwich compounds $\left[\mathrm{Fe}\left(\eta^{5}-\mathrm{C}_{2} \mathrm{R}_{2} \mathrm{P}_{3}\right)_{2}\right]$, and $\left[\mathrm{Fe}\left(\eta^{5}-\mathrm{C}_{3} \mathrm{R}_{3} \mathrm{P}_{2}\right)\left(\eta^{5}-\mathrm{C}_{2} \mathrm{R}_{2} \mathrm{P}_{3}\right)\right]\left(\mathrm{R}=\mathrm{Bu}{ }^{\mathrm{t}}\right)$. J. Chem. Soc., Chem. Commun. 15, 1146-1148 (1987)

Beach, D.H.: Some reasons for teaching descriptive chemistry. J. Chem. Educ. 61, 521 (1984)

Berzelius J.J.: Essai sur la nomenclature chimique. Journal de Physique, de Chimie, d'Histoire Naturelle LXXIII, 253-286 (1811)

Carenco, S., Portehault, D., Boissière, C., Mézailles, N., Sanchez, C.: Nanoscaled metal borides and phosphides: recent developments and perspectives. Chem. Rev. 113(10), 7981-8065 (2013)

Chedd, G.: Half-Way Elements: The Technology of Metalloids. Doubleday, New York (1969)

Choppin, G.R., Johnsen, R.H.: Introductory Chemistry. Addison-Wesley, Reading (1972)

Clark, S., Zaug, J.M.: Compressibility of cubic white, orthorhombic black, rhombohedral black, and simple cubic black phosphorus. Phys. Rev. B. 82, 134111-1-134111-6 (2010)

Cotton, F., Wilkinson, G., Murillo, C.A., Bochmann, M.: Advanced Inorganic Chemistry, 6th ed., p 554. Wiley, New York (1999)

Cronyn, M.W.: The proper place for hydrogen in the periodic table. J. Chem. Educ. 80(8), 947-951 (2003)

Desch, C.H.: Intermetallic Compounds. Longmans, p. 86. Green and Co., New York (1914)

DeVries, R.C.: Naturally occurring intermetallic compounds. In: Westbrook J.H., Fleischer R.L. (eds.) Intermetallic Compounds: Principles and Practices, p. 625. Wiley, Chichester (1995)

Dillon, K.B., Mathey, F., Nixon, J.F.: Phosphorus: The Carbon Copy: From Organophosphorus to PhosphaOrganic Chemistry. Wiley, Chichester (1998)

Dingle, A. The Elements: An Encyclopedic Tour of the Periodic Table. Quad Books, Brighton, p. 101, (2017): “...with 'no-doubt' metals on the far left of the table, and 'no-doubt' non-metals on the far right...the gap between the two extremes is bridged first by the poor [frontier] metals, and then by the metalloids - which, perhaps by the same token, might collectively be renamed the "poor non-metals"."

Dye, J.L.: Compounds of alkali metal anions. Angew. Chem. Int. Ed. Engl. 18(8), 587-598 (1979)

Entwistle, N.: Student Learning and Understanding: A Research Perspective with Implications for Teaching, p. 129. Academic Press, London (2018)

Ferro, R., Saccone, A.: Intermetallic Chemistry, p. 518. Elsevier, Amsterdam (2008)

Friend, J.N.: A Text-book of Inorganic Chemistry, vol. 1. Charles Griffin and Company, London, p. 9 (1914): "Usually, the metalloids possess the form or appearance of metals, but are more closely allied to the non-metals in their chemical behaviour"

Goldschmidt, H.J.: Interstitial Alloys, pp. 43-44. Butterworths, London 296 (1967)

Greenwood, N.N., Earnshaw, A.: Chemistry of the Elements, 2nd edn, p. 223. Butterworth-Heinemann, Oxford (1998)

Greenwood, N.N.: Main group element chemistry at the millennium. J. Chem. Soc. Dalton Trans. 14, 20552066 (2001) 
Grimvall, G.: Electrical and thermal conductivity and related transport properties. In: Kumashiro, Y. (ed.) Electric Refractory Materials, pp. 173-190. Marcel Dekker, New York (2005)

Hampel, C.A., Hawley, G.G.: Glossary of Chemical Terms. Van Nostrand Reinhold, New York (1976)

Hathaway, G.J., Proctor, N.H.: Proctor and Hughes Chemical Hazards of the Workplace, 5th edn, p. 402. Wiley, Hoboken (2004)

Hermann, A., Hoffmann, R., Ashcroft, N.W.: Condensed astatine: monatomic and metallic. Phys. Rev. Lett. 111, 11604-1-11604-5 (2013)

Jensen, W.B.: Classification, symmetry, and the periodic table. Comput Maths Appls. 12B(1-2), 487-510 (1986)

Jones, B.W.: Pluto: Sentinel of the Outer Solar System. Cambridge University, Cambridge (2010)

Kent, J.A.: Kent and Riegel's Handbook of Industrial Chemistry and Biotechnology, 11th ed, vol. 1, p. 104. Springer, New York (2010)

Kneen, W.R., Rogers, M.J.W., Simpson, P.: Chemistry, Facts Patterns, and Principles. Addison-Wesley, London (1972)

Lange, S., Schmidt, P., Nilges, T.: $\mathrm{Au}_{3} \mathrm{SnP}_{7} @$ Black Phosphorus: an easy access to black phosphorus. Inorg. Chem. 46(10), 4028-4035 (2007)

Larrañaga, M., Lewis (Sr), R. J., Lewis, R.: Hawley's Condensed Chemical Dictionary, 16th ed., p. 988. Wiley, Hoboken (2016)

Leach, M.: Concerning electronegativity as a basic elemental property and why the Periodic table is usually represented in its medium form. Found. Chem. 15(1), 13-29 (2013)

MacKay, K.M., MacKay, R.A., Henderson, W.: Introduction to Modern Inorganic Chemistry, 6th ed. Nelson Thornes, Cheltenham, p. 204 (2002); Rayner-Canham, G. Organizing the transition metals. In Scerri E., Restrepo G. (eds.) Mendeleev to Oganesson: A Multidisciplinary Perspective on the Periodic Table. Oxford University Press, New York, pp. 195-205 (2018)

Masterton, W.L., Slowinski, E.J.: Chemical Principles, 4th edn, p. 160. WB Saunders, Philadelphia (1977)

Miller, J.S.: Viewpoint: metalloids_An electronic band structure perspective. Eur. J. Chem. 25, 1117711179 (2019)

Miller, T.S., Belen, A., Suter, T.M., Sella, A., Corà, A., McMillan, P.F.: Carbon nitrides: synthesis and characterization of a new class of functional materials. Phys. Chem. Chem. Phys. 24, 15613-15638 (2017)

Moeller, T., Bailar, J.C., Kleinberg, J., Guss, C.O., Castellion, M.E., Metz, C.: Chemistry, with Inorganic Qualitative Analysis, 3rd edn. Harcourt Brace Jovanovich, San Diego (1989)

Monteil, Y., Vincent, H.: Phosphorous compounds with the VI B group elements. Z. Naturforsch. B. J. Chem. Sci. 31b(5), 668-672 (1976)

Moss, T.S.: Photoconductivity in the elements. Butterworths Scientific, London, pp. 180, 202 (1952). For amorphous selenium, the increase in conductivity is a thousand-fold; for "metallic" selenium the increase is from three to as much as two-hundred fold. Mikla, V.I.; Mikla, V.V.: Amorphous Chalcogenides: The Past, Present and Future. Elsevier, Boston, p. 63 (2012); Yost, D.M., Russell, H. Systematic Inorganic Chemistry of the Fifth-and-Sixth-Group Nonmetallic Elements. Prentice-Hall, New York, p. $282(1946)$

Nelson, P.G.: Introduction to Inorganic Chemistry: Key Ideas and their Experimental Basis. Ventus Publishing ApS. https://bookboon.com/en/introduction-to-inorganic-chemistry-ebook, p. 57 (2011)

Newth, G.S.: A Text-book of Inorganic Chemistry, pp. 7-8. Longmans, Green, and Co, London (1894)

Oderberg, D.S.: Real Essentialism. Routledge, New York (2007)

Oyama, S.T.: Transition metal carbides, nitrides, and phosphides. In: Ertl, G., Knözinger, H, Schüth, F., Weitkamp, J. (eds.). Handbook of Heterogeneous Catalysis, 2nd ed., vol. 1, p. 342. Wiley, Weinheim (2008)

Pan S., Jana G., Merino, G., Chattaraj, P. K.: Noble-noble strong union: Gold at its best to make a bond with a noble gas atom. ChemistryOPEN. 8 (2), $173-187$ [176] (2019)

Phillips, C. S. G., Williams R. J. P.: Inorganic Chemistry, I: Principles and Non-metals. Clarendon Press, Oxford, p. 609 (1965a)

Phillips, C. S. G., Williams R. J. P.: Inorganic Chemistry, I: Principles and Non-metals. Clarendon Press, Oxford, p. 620 (1965b): Alloy formation being especially prevalent in the case of compounds of silicon, germanium, arsenic, and antimony with frontier metals

Phillips, C. S. G., Williams R. J. P.: Inorganic Chemistry, II: Metals. Oxford University Press, Oxford, p. 459 (1966)

Randall, L.: Warped passages: Unravelling the universe's hidden dimensions. Penguin Books, London, p. 193 (2006)

Rang, P.J.F.: The periodic arrangement of the elements. Chem. News 67, 178 (1893)

Rayner-Canham, G.: Periodic patterns. J. Chem. Educ. 77(8), 1053-1056 (2000)

Rayner-Canham, G.: Isodiagonality in the periodic table. Found. Chem. 13(2), 121-129 (2011) 
Rayner-Canham, G.: Organizing the transition metals. In Scerri E., Restrepo G. (eds.). Mendeleev to Oganesson: A Multidisciplinary Perspective on the Periodic Table. Oxford University Press, New York, pp. 195-205 [202] (2018)

Rayner-Canham, G., Overton, T.: Descriptive Inorganic Chemistry, 5th edn. W. H. Freeman and Company, New York (2010)

Redko, M.Y., Huang, R.H., Jackson, J.E., Harrison, J.F., Dye, J.L.: Barium azacryptand sodide, the first alkalide with an alkaline earth cation, also contains a novel dimer, $\left(\mathrm{Na}_{2}\right)^{2-}$. J. Am. Chem. Soc. 125(8), 2259-2263 (2003)

Richey, R.C., Klein, J.D., Tracey, M.W.: The Instructional Design Knowledge Base: Theory, Research, and Practice. Routledge, New York (2010)

Rochow, E.G.: The Metalloids. D. C. Heath and Company, Boston (1966)

Roher, G.S.: Structure and Bonding in Crystalline Materials. Cambridge University Press, Cambridge (2001)

Roy, A.K., Burns, G.T., Grigora, S., Lie, G.C.: Poly(alkyl/aryloxothiazenes), $[\mathrm{N}=\mathrm{S}(\mathrm{O}) \mathrm{R}]_{\mathrm{n}}$ : New direction in inorganic polymers. In: Wisian-Neilson, P., Alcock, H.R., Wynne, K.J. (eds.) Inorganic and Organometallic Polymers II: Advanced Materials and Intermediates, pp. 344-357. American Chemical Society, Washington DC (1994)

Russell, A. M.; Lee, K. L.: Structure-property relations in nonferrous metals. Wiley, Hoboken, NJ (2005). Re the frontier metal parlance, the authors write (p. 419): “...bismuth and group 16 element polonium are generally considered to be metals, although they occupy "frontier territory" on the periodic table, adjacent to the nonmetals."

Scerri, E.: A critique of Weisberg's view on the periodic table and some speculations on the nature of classifications. Found. Chem. 14 (3), pp. 275-284 [282-283] (2012)

Scerri E. R., Parsons W.: What elements belong in group 3 of the periodic table? In Scerri E., Restrepo R. (eds). Mendeleev to Oganesson: A Multidisciplinary Perspective on the Periodic Table. Oxford University Press, New York, pp 140-151 [145-146] (2018)

Schultz, E.: Reflections catalyzed by an assault on a favorite principle. Journal of Chemical Education. 87 (5), pp. 472-473 [473] (2010)

Sorensen, E. M. B.: Metal Poisoning in Fish. CRC Press, Boca Raton, Florida, p. 3 (1991)

Steele, D.: The Chemistry of the Metallic Elements. Pergamon Press, Oxford (1966)

Stein, L.: New evidence that radon is a metalloid element: ion-exchange reactions of cationic radon. J. Chem. Soc., Chem. Commun. 22, 1631-1632 (1985)

Stein, L.: The chemistry of radon. Radiochim. Acta 32, 163-171 (1983)

Stoyanov, E.S., Stoyanova, I.V., Reed, C.A.: The structure of the hydrogen ion $\left(\mathrm{H}_{\mathrm{aq}}^{+}\right)$. J. Am. Chem. Soc. 132(5), 1484-1485 (2010)

Tiouitchi, G., Ait Ali, M., Benyoussef, A., Hamedoun, M., Lachgar, A., Benaissa, M., Kara, A., Ennaoui, A., Mahmoud, A., Boschini, F., Oughaddou, H., El Kenz, A., Mounkachi, O.: An easy route to synthesize high-quality black phosphorus from amorphous red phosphorus. Mater. Lett. 236, 56-59 (2019)

Vernon, R.E.: Which elements are metalloids? J. Chem. Educ. 90(12), 1703-1707 (2013)

Wang, F.E.: Bonding Theory for Metals and Alloys. Elsevier, Amsterdam, p. 192 (2005)

Whitten, K.W., Gailey, K.D., Davis, R.E.: General Chemistry with Qualitative Analysis, 3rd edn, pp. 905906. Saunders College Publishing, Philadelphia (1988)

Wiberg, N.: Inorganic chemistry. Academic Press, Berlin (2001), pp. 256, 517: Wiberg addresses the interstitial hydrides, carbides, and nitrides. Oyama (2008) writes that the carbides, nitrides and phosphides are covalent for the main group elements aside from the group 1 and 2 metals, which form salt-like compounds. Goldschmidt (1967) assesses the phosphides, sulfides, and selenides as being borderline elements located between the true interstitial elements $\mathrm{C}, \mathrm{N}, \mathrm{O}$ and those capable of forming genuine intermetallic compounds (As, Sb, Bi). DeVries (1995) observes that most sulfides are not intermetallic compounds. Ferro and Saccone (2008) note that many of the selenides and tellurides formed with transition metals may be described as metallic alloys

Wikipedia: 'Post-transition metals'. Accessed 12 Nov (2019a)

Wikipedia: 'Metalloid'. Accessed 9 Nov (2019b)

Wikipedia: 'Nonmetal'. Accessed 13 Nov (2019c)

Woodward, P. M., Mizoguchi H., Kim Y.-I., Stolzfus M. W.: The electronic structure of metal oxides. In Fierro J. L. G. (ed.) Metal Oxides: Chemistry and Applications, CRC Press, Boca Raton, pp. 133-194 [134] (1999)

Young, R.V., Sessine, S. (eds.): World of Chemistry. Gale Group, Farmington Hills (2000)

Publisher's Note Springer Nature remains neutral with regard to jurisdictional claims in published maps and institutional affiliations. 